\title{
Maochieh Chi* \\ Effects of the alkaline solution/binder ratio and curing condition on the mechanical properties of alkali-activated fly ash mortars
}

DOI 10.1515/secm-2015-0305

Received August 14, 2015; accepted December 30, 2015; previously published online April 6, 2016

Abstract: The study investigates the effects of the alkaline solution/binder ratio and the curing condition on the mechanical properties of alkali-activated fly ash (AAFA) mortars. Class F fly ash was used as the raw material, and sodium hydroxide and liquid sodium silicate were used for the preparation of alkaline activators. Three alkaline solution-to-binder ratios (0.35, 0.5, and 0.65) and four different initial curing conditions (curing in air at ambient temperature for $24 \mathrm{~h}, 30^{\circ} \mathrm{C}$ for $24 \mathrm{~h}, 65^{\circ} \mathrm{C}$ for $12 \mathrm{~h}$, and $85^{\circ} \mathrm{C}$ for $6 \mathrm{~h}$ ) were considered. Test results show that AAFA mortars with alkaline solution-to-binder ratio of 0.35 had higher compressive strength, lower drying shrinkage, lower water absorption, and lower initial surface absorption rate than the other mortars. Furthermore, the curing condition influenced the compressive strength development and drying shrinkage of AAFA mortars at early ages. AAFA mortars cured at $65^{\circ} \mathrm{C}$ for $12 \mathrm{~h}$ appeared to have superior mechanical properties. XRD demonstrates that the hydration products of AAFA mortars are mainly amorphous alkaline aluminosilicate gel, which attributed to the compressive strength. Consequently, the alkaline solution-to-binder ratio significantly affects more the mechanical properties than the curing condition based on the presented results.

Keywords: alkali-activated fly ash (AAFA); alkaline solution-to-binder ratio; curing condition; mechanical property.

\section{Introduction}

The use of alkali-activated fly ash (AAFA) instead of ordinary Portland cement (OPC) in concrete manufacturing is environmentally beneficial because the manufacturing

*Corresponding author: Maochieh Chi, Department of Fire Science, WuFeng University, 117, Sec 2, Chiankuo Road, Minshiung Township, Chiayi County 621, Taiwan, ROC, e-mail: jackchi@wfu.edu.tw process of AAFA requires lesser energy and produces lower $\mathrm{CO}_{2}$ emissions and industrial waste. AAFA is prepared using a chemical process in which fly ash is mixed with strong alkaline solutions and cured at a moderate temperature, and it is in the form of well-compacted cementitious composites [1-3]. In a strongly alkaline environment, silica and alumina in fly ash particles are dissolved, and they form geopolymeric gel $[1,4]$. This binder, often called geopolymer, has considerable potential as an alternative to OPC because of its excellent mechanical properties, such as high strength, fire resistance, acid resistance, high thermal stability, and environmental friendliness [4-9]. The formation and properties of a geopolymer are affected by the mix composition and reaction conditions such as $\mathrm{Al}_{2} \mathrm{O}_{3} / \mathrm{SiO}_{2}$, alkali concentration, curing temperature, curing time, alkaline solution/binder ratio, and the alkaline solution $\mathrm{pH}$ value $[2,10-16]$.

Many studies $[17,18]$ have addressed the effect of the water/cement ratio on the mechanical properties of OPC. For example, Odler and Röbler [17] indicated that the water/cement ratio affects both the physical properties of OPC and the composition of the calcium silicate hydrate (C-S-H) gel produced during hydration. The findings mentioned above may be extrapolated to alkaline cements. Indeed, the effect of the alkaline solution/binder ratio on alkali-activated systems has been reported in several studies [19-22]. Zuhua et al. [20] found that high liquid/ solid ratio could accelerate the dissolution of raw materials. Also, Yao et al. [21] showed that higher liquid/solid ratios increased the geopolymerization period. However, the approach in which it affects the nature of the reaction products has not been studied fully. Moreover, increasing the alkaline solution/binder ratio for these materials not only increases the water content, but also increases the amount of alkaline cations and hydroxide ions $\left(\mathrm{OH}^{-}\right)$in the alkali-activated systems [22].

The alkali activation of fly ash requires the supply of external energy in the form of heat for the formation of alkali aluminosilicates because AAFA pastes harden slowly at ambient temperature. Alkali-activated binders with appreciable mechanical properties have been produced at a wide range of temperatures, from $20^{\circ} \mathrm{C}$ to $90^{\circ} \mathrm{C}$ 
[23-25]. The degree of reaction of the fly ash and silica in the aluminosilicates formed increases with the thermal curing time. When the thermal curing time is increased, the gel undergoes polymerization, and its structure becomes highly ordered [26]. Furthermore, curing conditions have a strong effect on both early age and final mechanical properties of geopolymer materials [27-30]. Kovalchuk et al. [28] found that curing in a covered mold at $95^{\circ} \mathrm{C}$ produced geopolymer materials with the highest compressive strength, and they recommended dry curing at $150^{\circ} \mathrm{C}$ for $\mathrm{NaOH}$-based systems (low $\mathrm{SiO}_{2} / \mathrm{Al}_{2} \mathrm{O}_{3}$ ratio); furthermore, they observed that steam curing at $95^{\circ} \mathrm{C}$ had a moderate effect on strength development. Swanepoel and Strydom [29] conducted a study on geopolymers cured at $40^{\circ} \mathrm{C}, 50^{\circ} \mathrm{C}, 60^{\circ} \mathrm{C}$, and $70^{\circ} \mathrm{C}$ for different durations and found that the optimal curing conditions involved a temperature of $60^{\circ} \mathrm{C}$ and a duration of $48 \mathrm{~h}$. Chi [30] investigated the physical and mechanical properties and durability of alkali-activated slag concrete (AASC) for three different curing conditions and found that curing at $80 \%$ relative humidity $(\mathrm{RH})$ and a temperature of $60^{\circ} \mathrm{C}$ yielded optimal AASC performance; AASC obtained through air curing and saturated limewater curing showed the next highest performance. Geopolymers formed at room temperature are amorphous. With an increase in the temperature, crystalline phases begin to appear. Most research has been conducted by curing at approximately 95\% RH and in the temperature range $30-85^{\circ} \mathrm{C}[1,28,31-33]$. However, no detailed study has been conducted on the effect of the curing temperature on the geopolymer properties.

It is clear that there is still a large number of influential factors and complicated problems, and particular studies cannot provide all the answers. So then, further investigations regarding alkali-activated binding materials need to be done. The aim of this study is to investigate the effect of the alkaline solution/binder ratio and the curing condition on the mechanical properties of AAFA mortars. Three alkaline solution/binder ratios (0.35, 0.5, and 0.65) and four different initial curing conditions (curing in air at ambient temperature for $24 \mathrm{~h}, 30^{\circ} \mathrm{C}$ for $24 \mathrm{~h}, 65^{\circ} \mathrm{C}$ for $12 \mathrm{~h}$, and $85^{\circ} \mathrm{C}$ for $6 \mathrm{~h}$ ) were considered.

\section{Materials and methods}

\subsection{Materials}

Class F fly ash (FA) from Xingda Power Plant in Kaohsiung, Taiwan, was used as the main aluminum and silicate source for synthesizing a geopolymeric binder. The chemical composition of the FA was determined by X-ray fluorescence spectrometry, and it is listed in Table 1. The specific gravity and specific surface area of the FA were 2.06 and $0.237 \mathrm{~m}^{2} / \mathrm{g}$, respectively. Standard sand conforming to ASTM C778 [34] was used as the fine aggregate for preparing geopolymer mortars. The maximum grain size and specific gravity of the standard sand were $2.5 \mathrm{~mm}$ and 2.65 , respectively. The most used alkaline activators were a mixture of sodium hydroxide $(\mathrm{NaOH})$ and sodium silicate $\left(\mathrm{Na}_{2} \mathrm{O} \cdot \gamma \mathrm{SiO}_{2}\right)$ [35]. In this study, the alkaline activation of the FA was performed using sodium hydroxide pellets with a density of $2130 \mathrm{~kg} / \mathrm{m}^{3}$ and sodium silicate solution $\left(\mathrm{Na}_{2} \mathrm{O} \cdot \gamma \mathrm{SiO}_{2} \cdot \mathrm{nH}_{2} \mathrm{O}\right)$ consisting of $29.2 \% \mathrm{SiO}_{2}, 14.8 \% \mathrm{Na}_{2} \mathrm{O}$, and $56.0 \% \mathrm{H}_{2} \mathrm{O}$ by mass. Furthermore, $\mathrm{Na}_{2} \mathrm{SiO}_{3}$ and $\mathrm{NaOH}$ solutions were prepared 1 day before their use.

\subsection{Mix design and specimen preparation}

AAFA geopolymer specimens were prepared from fly ash, sodium hydroxide, and sodium silicate. Alkaline solution-to-binder ratios of $0.35,0.5$, and 0.65 , denoted by M3, M5, and M6, respectively, were selected to produce AAFA mortars. Sodium oxide $\left(\mathrm{Na}_{2} \mathrm{O}\right)$ with a mass of 121 $\mathrm{kg}$ per cubic meter of mortar and liquid sodium silicate with a modulus ratio (mass ratio of $\mathrm{SiO}_{2}$ to $\mathrm{Na}_{2} \mathrm{O}$ ) of 1.23 were used as alkaline activators. The sand/binder ratio was constant at 2.75 . The mortar mix proportions are presented in Table 2. The mortar was mixed in a mechanical mixer. Subsequently, the mixture was poured into steel molds. The specimens were cast and kept in steel molds for $24 \mathrm{~h}$. The temperature and the curing duration strongly influence the formation of the amorphous aluminosilicate network. To balance the temperature and curing duration to achieve optimal mechanical performance, before demolding, the specimens were subjected to four different curing conditions with temperatures ranging from

Table 1: Chemical compositions of fly ash.

\begin{tabular}{lr}
\hline Chemical compositions (\%) & Fly ash \\
\hline Calcium oxide, $\mathrm{CaO}$ & 2.82 \\
Silicon dioxide, $\mathrm{SiO}_{2}$ & 56.48 \\
Aluminum oxide, $\mathrm{Al}_{2} \mathrm{O}_{3}$ & 20.34 \\
Ferric oxide, $\mathrm{Fe}_{2} \mathrm{O}_{3}$ & 6.61 \\
Sulfur trioxide, $\mathrm{SO}_{3}$ & 0.25 \\
Sodium oxide, $\mathrm{Na}_{2} \mathrm{O}$ & 0.33 \\
Potassium oxide, $\mathrm{K}_{2} \mathrm{O}$ & 0.8 \\
Magnesium oxide, $\mathrm{MgO}$ & 0.93 \\
Loss on ignition, L.O.I. & 2.76 \\
Others & 8.68 \\
\hline
\end{tabular}


Table 2: Mix proportions of AAFA mortars.

\begin{tabular}{|c|c|c|c|c|c|c|c|c|c|}
\hline \multirow[t]{2}{*}{ Mix no. } & \multirow{2}{*}{$\begin{array}{r}\text { Alkaline solution/ } \\
\text { binder ratio }\end{array}$} & \multirow{2}{*}{$\begin{array}{r}\mathrm{SiO}_{2} / \mathrm{Na}_{2} \mathrm{O} \\
\text { ratio }\end{array}$} & \multirow{2}{*}{$\begin{array}{r}\text { Water } \\
\left(\mathrm{kg} / \mathrm{m}^{3}\right)\end{array}$} & \multirow{2}{*}{$\begin{array}{l}\mathrm{Na}_{2} \mathrm{SiO}_{3} \\
\left(\mathrm{~kg} / \mathrm{m}^{3}\right)\end{array}$} & \multirow{2}{*}{$\begin{array}{r}\mathrm{NaOH} \\
\left(\mathrm{kg} / \mathrm{m}^{3}\right)\end{array}$} & \multirow{2}{*}{$\begin{array}{r}F A \\
\left(\mathrm{~kg} / \mathrm{m}^{3}\right)\end{array}$} & \multirow{2}{*}{$\begin{array}{r}\text { Fine Agg. } \\
\left(\mathrm{kg} / \mathrm{m}^{3}\right)\end{array}$} & \multicolumn{2}{|c|}{ Activator $\left(\mathrm{kg} / \mathrm{m}^{3}\right)$} \\
\hline & & & & & & & & $\mathrm{SiO}_{2}$ & $\mathrm{Na}_{2} \mathrm{O}$ \\
\hline M3 & 0.35 & 1.23 & 107.7 & 78.7 & 14.6 & 574 & 1581 & 28.3 & 23.0 \\
\hline M5 & 0.5 & 1.23 & 178.3 & 72.3 & 13.4 & 528 & 1453 & 26.0 & 21.1 \\
\hline M6 & 0.65 & 1.23 & 241 & 66.9 & 9.6 & 489 & 1345 & 24.0 & 19.5 \\
\hline
\end{tabular}

ambient temperature $\left(23^{\circ} \mathrm{C}\right)$ to $85^{\circ} \mathrm{C}$ and curing times ranging from 6 to $24 \mathrm{~h}$. In other words, the specimens were exposed to air at ambient temperature for $24 \mathrm{~h}, 30^{\circ} \mathrm{C}$ for $24 \mathrm{~h}, 65^{\circ} \mathrm{C}$ for $12 \mathrm{~h}$, and $85^{\circ} \mathrm{C}$ for $6 \mathrm{~h}$; these conditions are denoted by A, B, C, and D, respectively. After the initial curing, they were shifted to a curing room with $80 \% \mathrm{RH}$ and a temperature of $25^{\circ} \mathrm{C}$; they were stored in the room until they were tested.

\subsection{Methods}

\subsubsection{Compressive strength test}

Compressive strength tests were conducted on the specimens according to ASTM C109 [36]. For each mixture, $50 \mathrm{~mm} \times 50 \mathrm{~mm} \times 50 \mathrm{~mm}$ cubes were prepared, and three specimens of each mixture were tested at the ages of 7 , 14 , and 28 days to determine the average compressive strength.

\subsubsection{Drying shrinkage test}

The measurements of length change as scale of the drying shrinkage of mortar were conducted based on ASTM C596 [37]. Prismatic specimens with dimensions of $285 \mathrm{~mm} \times 25 \mathrm{~mm} \times 25 \mathrm{~mm}$ were used for drying shrinkage measurements. After 1 day, the initial lengths $\left(L_{\mathrm{i}}\right)$ of demolded shrinkage specimens were measured using a digital comparator with an accuracy of $0.001 \mathrm{~mm}$. After curing, the lengths $\left(L_{\mathrm{x}}\right)$ of the shrinkage specimens were measured at the ages of 7,14 , and 28 days. The shrinkage value for each age is the average of three readings. During the drying shrinkage test, the specimens were kept at the temperature of $25^{\circ} \mathrm{C}$ in a relative humidity of $80 \%$. The drying shrinkage was then calculated from the following formula:

$$
\text { DS (\%) }\left(L_{\mathrm{i}}-L_{\mathrm{x}}\right) / G \times 100
$$

where $G$ is the nominal effective length.

\subsubsection{Water absorption}

Water absorption was determined in accordance with ASTM C642 [38]. The cubes were first placed in an oven at $105 \pm 5^{\circ} \mathrm{C}$ for $24 \mathrm{~h}$ and then weighed $\left(W_{\mathrm{d}}\right)$. Next, they were immersed in water for $24 \mathrm{~h}$ and then weighed again $\left(W_{\mathrm{s}}\right)$. The parameter $W_{\mathrm{s}}$ was considered as the saturated weight. It took up to $24 \mathrm{~h}$ for the specimens. The water absorption (WA) was then calculated using the following formula $[39,40]$ :

$$
W A(\%)=\left(W_{\mathrm{s}}-W_{\mathrm{d}}\right) / W_{\mathrm{d}} \times 100
$$

The porosity $(P)$ was calculated from the expression

$$
P(\%)=\left(W_{\mathrm{s}}-W_{\mathrm{d}}\right) / V \times 100
$$

where $V$ is the bulk volume of the specimen.

\subsubsection{Initial surface absorption test}

The initial surface absorption test (ISAT) of concrete is to indicate the water flow into the surface of a dry, flat concrete surface. The principle of test is to determine the time taken for a quantity of water to flow through a standardized glass tube onto a known area of concrete surface. The ISAT was performed according to the test method described in BS 1881-208 [41]. The specimens were cast in 100-mm cubes for measuring the initial surface absorption rate. The specimens were demolded $24 \mathrm{~h}$ after casting and then cured for 28 days. At least three specimens were prepared for obtaining the average value of the initial surface absorption test. The specimens were oven dried to constant weight at a temperature of $105 \pm 5^{\circ} \mathrm{C}$ prior to the test. The test consists of the measurement of water flow into the test specimen through a known surface area. The initial surface absorption was measured at intervals of 10, 30, and 60 min after the start of testing. The initial surface absorption rate was expressed in milliliters per square meter per second $\left(\mathrm{ml} /\left(\mathrm{m}^{2} \cdot \mathrm{s}\right)\right)$. 


\subsubsection{Mercury intrusion porosimetry}

The mercury intrusion porosimetry (MIP) test was performed in accordance with ASTM D4404-10 [42], was and it involved injecting mercury into dried specimens. Specimens aged 28 days were dried in an oven at $105^{\circ} \mathrm{C}$ for $24 \mathrm{~h}$ before testing. Pressure, which was progressively incremented, was applied to mercury, and the intrusion of mercury was monitored at each increment. The intruded volume was used to determine the pore size distribution. Furthermore, the diameter of cylindrical pores was calculated using the Washburn equation [43, 44]:

$$
d=-\Phi \gamma \cos \theta / p
$$

where $d$ is the cylindrical pore diameter, $\Phi$ is the pore shape factor, $\gamma$ is the surface tension of mercury, $\theta$ is the contact angle of mercury, and $p$ is the applied pressure. The contact angle was set at $130^{\circ}$, the surface tension of mercury was assumed to be $0.485 \mathrm{~N} / \mathrm{m}$, the measuring pressure ranged from 0.7 to $210 \mathrm{MPa}$, and the measurable pore size ranged from 0.003 to $360 \mu \mathrm{m}$.

\subsubsection{X-ray diffraction analysis}

X-ray diffraction is a non-destructive technique used to determine crystalline phases present within the investigated material. For X-ray diffraction (XRD) analysis, randomly oriented powder specimens (approximately 1 $\mathrm{g}$ in weight) were prepared by grinding small portions of the dried specimens. XRD graphs were obtained using a Siemens D5000 X-ray diffractometer and CuK $\alpha$ radiation at room temperature. The diffractograms were scanned in the $2 \theta$ range $10^{\circ}-80^{\circ}$ at $0.05^{\circ}$ intervals. The components of the sample were identified by comparing them with standards established by the International Center for diffraction data.

\section{Results and discussion}

\subsection{Compressive strength}

The compressive strength developments of AAFA mortars with various alkaline solution-to-binder ratios and cured under four different conditions at the ages of 7, 14, and 28 days are shown in Figures 1-3. As expected, the compressive strength of all AAFA mortars increased with age and decreased with an increase in the alkaline solutionto-binder ratio.

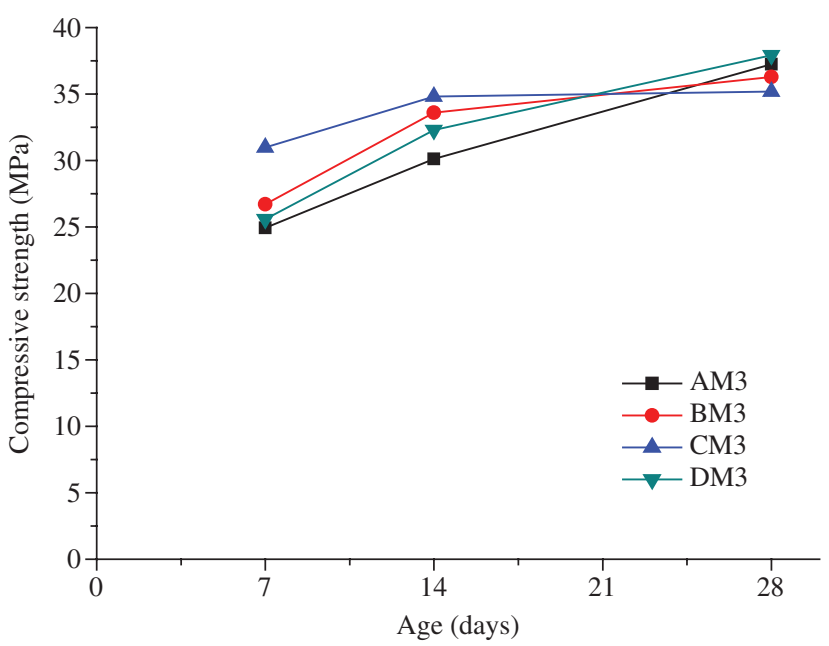

Figure 1: Compressive strength development of AAFA geopolymer with the alkaline solution/binder ratio of $0.35 \mathrm{vs}$. age.

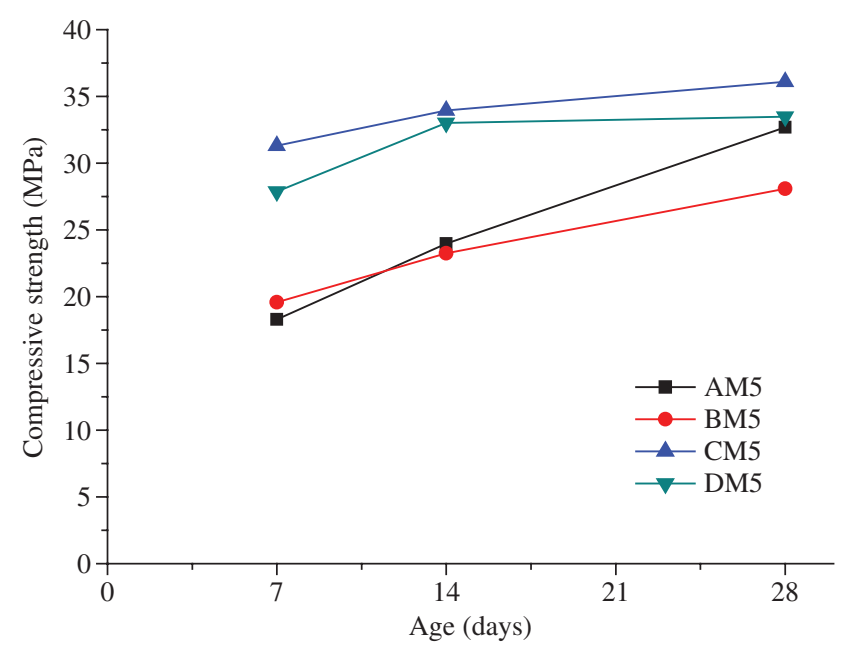

Figure 2: Compressive strength development of AAFA geopolymer with the alkaline solution/binder ratio of $0.5 \mathrm{vs}$. age.

As shown in Figure 1, the compressive strength of AM3 steadily increased with age, and it amounted to $24.9 \mathrm{MPa}$ for the 7-day-old specimen, 30.2 MPa for the 14-day-old specimen, and $37.2 \mathrm{MPa}$ for the 28-day-old specimen. The 28-day compressive strength of AM3 indicated an increase of $50 \%$ compared with the 7 -day compressive strength. The compressive strength development of DM3 is highly similar to that of AM3. A higher compressive strength was observed for the 7-day-old CM3 (AAFA mortars cured at $\left.65^{\circ} \mathrm{C}\right)$. The increase in the compressive strength lasted for 14 days and then began to level off; the compressive strength was $31 \mathrm{MPa}$ at the age of 7 days, $34.8 \mathrm{MPa}$ at the age of 14 days, and $35.2 \mathrm{MPa}$ at the age of 28 days. For AAFA mortars with the alkaline solution-to-binder ratio of 


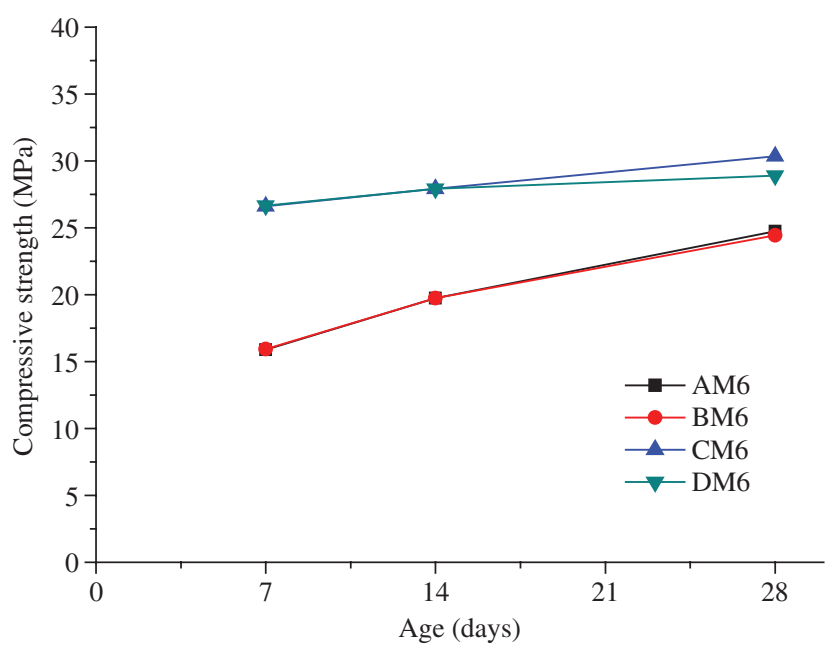

Figure 3: Compressive strength development of AAFA geopolymer with the alkaline solution/binder ratio of $0.65 \mathrm{vs}$. age.

0.35 , the curing temperature appeared to have no appreciable influence on compressive strength development, particularly in older specimens. As shown in Figure 2, the compressive strengths of the AM5 and BM5 mortars (AAFA mortars cured at ambient temperature and $30^{\circ} \mathrm{C}$, respectively) were lower than those of the CM5 and DM5 mortars at the age of 7 days. At ambient temperature, alkali activation of fly ash increased gradually, and an increase in the temperature accelerated the formation of a hardened structure, particularly in the early stages of the geopolymerization reaction, and enhanced the compressive strength. For example, CM5 mortar reached a compressive strength of $31.5 \mathrm{MPa}$, which was approximately twice that of AM5 mortars at the age of 7 days. However, the compressive strengths of the AM5 and BM5 mortars steadily increased for 28 days. For example, the compressive strength of AM5 was $18.4 \mathrm{MPa}$ at the age of 7 days, $24 \mathrm{MPa}$ at the age of 14 days, and 32.7 MPa at the age of 28 days. CM5 and DM5 (AAFA mortars cured at $65^{\circ} \mathrm{C}$ and $85^{\circ} \mathrm{C}$ ) showed a rapid increase in their compressive strength at the age of 7 days; however, the rate of increase in the compressive strength decreased after 14 days. The compressive strength of CM5 was $31.5 \mathrm{MPa}$ at the age of 7 days, $34.8 \mathrm{MPa}$ at the age of 14 days, and $35.2 \mathrm{MPa}$ at the age of 28 days. The 28-day compressive strength of CM5 was only approximately $10 \%$ greater than the 7-day compressive strength. The compressive strength development of DM5 was similar to that of CM5. However, in old specimens, the curing temperature has no appreciable influence on the compressive strength. As shown in Figure 3, the compressive strength development could be divided into two groups: one group consisted of AAFA mortars cured at ambient temperature and at $30^{\circ} \mathrm{C}$ (AM6 and BM6 mortars), and the other group comprised AAFA mortar cured at $65^{\circ} \mathrm{C}$ and $85^{\circ} \mathrm{C}(\mathrm{CM} 6$ and DM6 mortars). The compressive strength of the CM6 and DM6 mortars was higher than that of the AM6 and BM6 mortars for all ages. The compressive strength of AAFA mortars increased with the temperature because the geopolymerization reaction proceeded faster at higher temperatures, resulting in an increased amount of alkali-activated reaction products [27].

The results showed that both the alkaline solutionto-binder ratio and initial curing conditions appreciably influenced the compressive strength development of AAFA mortars. The lower the alkaline solution-to-binder ratio, the higher the compressive strength. Furthermore, the curing temperature plays a crucial role in determining the compressive strength development of AAFA mortars at early ages, particularly for AAFA mortars with the alkaline solution-to-binder ratios of 0.5 and 0.65 . The compressive strength of AAFA mortars cured at $65^{\circ} \mathrm{C}$ for $12 \mathrm{~h}$ was higher than that of AAFA mortars cured at other temperatures.

\subsection{Drying shrinkage}

Drying shrinkage is the volume change resulting from water loss in a specimen exposed to a dry environment during high-temperature curing. Specifically, it is the shrinkage, including autogenous shrinkage, occurring during the drying phase of the specimens. The drying shrinkage of AAFA mortars with various alkaline solutionto-binder ratios and cured at the four different conditions for 7, 14, and 28 days is shown in Figures 4-6. From these results, it is apparent that the drying shrinkage for

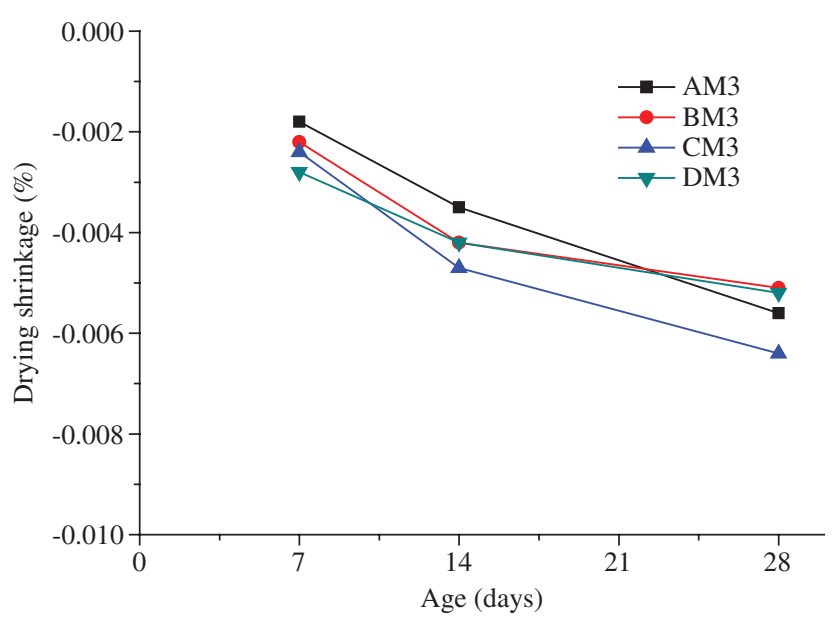

Figure 4: Drying shrinkage of AAFA geopolymer with the alkaline solution/binder ratio of 0.35 vs. age. 


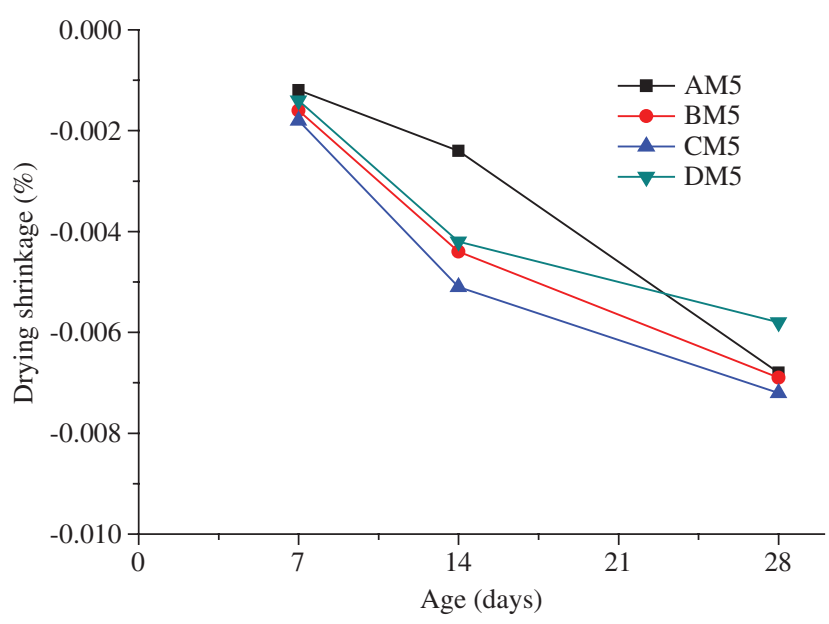

Figure 5: Drying shrinkage of AAFA geopolymer with the alkaline solution/binder ratio of $0.5 \mathrm{vs}$. age.

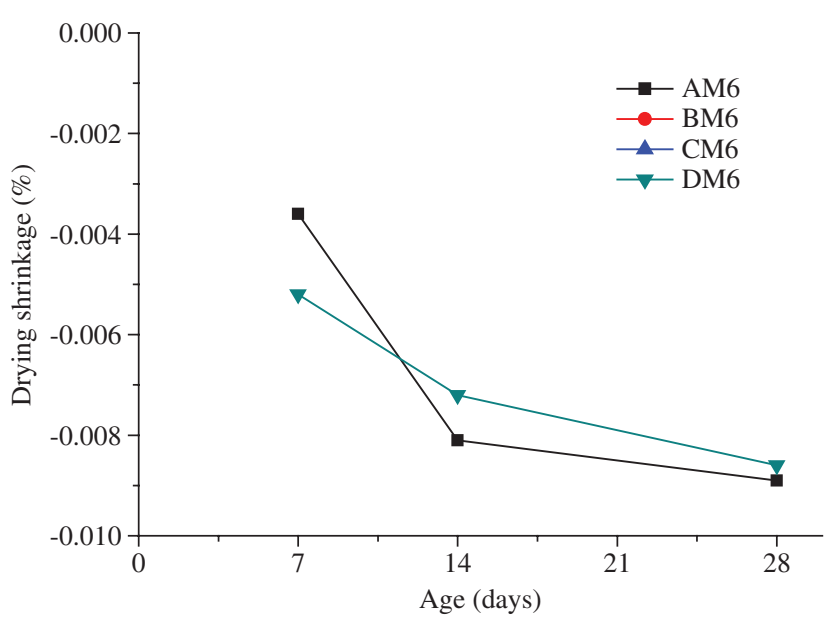

Figure 6: Drying shrinkage of AAFA geopolymer with the alkaline solution/binder ratio of $0.65 \mathrm{vs}$. age.

all AAFA mortars increased with their age and that the increase lasted for 28 days. The higher the alkaline solution-to-binder ratio, the higher the drying shrinkage.

As shown in Figure 4, the drying shrinkage of AAFA mortars with the alkaline solution-to-binder ratio of 0.35 showed a rapid increase at early ages. On the basis of the 7-day drying shrinkage, the specimens could be ordered as DM3 $>$ CM3 $>$ BM3 $>$ AM3. However, the rate of increase of drying shrinkage decreased after 14 days. The CM3 mortar (cured at $65^{\circ} \mathrm{C}$ ) had the highest drying shrinkage at the four curing temperatures: $0.0047 \%$ at the age of 14 days and $0.0064 \%$ at the age of 28 days. At early ages, hightemperature curing has an appreciable influence on the drying shrinkage of AAFA mortars because the high temperature accelerates the alkali-activation reaction of fly ash and increases the drying shrinkage of AAFA mortars.
With an increase in age, the effect of curing temperature has a less influence on the drying shrinkage of AAFA mortars. At a late age, the drying shrinkage of the DM3 mortar (cured at $85^{\circ} \mathrm{C}$ ) is almost the same as that of the BM3 mortar (cured at ambient temperature): 0.0042\% at the age of 14 days and $0.0052 \%$ at the age of 28 days. Figure 5 shows the drying shrinkage of AAFA mortars with the alkaline solution-to-binder ratio of 0.5 and cured at four different temperatures (AM5, BM5, CM5, and DM5). Except for the DM5 mortar, the drying shrinkage of AAFA mortars increased with the curing temperature. On the basis of the drying shrinkage, the specimens aged 7 and 14 days were ordered as CM5>BM5>DM3>AM3. After 14 days, the drying shrinkage of the AM5 mortars began to increase markedly. The 28-day drying shrinkage of the AM5 mortars was close to that of BM5, which had a drying shrinkage of $0.0068 \%$. This is because the alkali activation reaction was incomplete, leading to excess moisture and a high-drying shrinkage. The drying shrinkage of AAFA mortars with the alkaline solution-to-binder ratio of 0.65 and cured at four different temperatures (AM6, BM6, CM6, and DM6) is shown in Figure 6. High-temperature curing for over $12 \mathrm{~h}$ for AAFA mortars with the alkaline solution-to-binder ratio of 0.65 (BM6 and CM6) results in crack formation or deterioration, and hence, the drying shrinkages of BM6 and CM6 could not be determined during the curing period. Figure 7A and B show cracks in AAFA mortars with the alkaline solution-to-binder ratio of 0.65 and cured at $30^{\circ} \mathrm{C}$ for $24 \mathrm{~h}$ and at $65^{\circ} \mathrm{C}$ for $12 \mathrm{~h}$, respectively. At early ages, higher temperatures accelerate the geopolymerization reaction of AAFA mortars, resulting in higher drying shrinkage. However, at late ages, the drying shrinkage of AAFA mortars cured at high temperatures increases gradually because of a reduction in the amount of the alkaline solution.

\subsection{Water absorption and porosity}

The water absorption of 28-day-old AAFA mortars cured at different temperatures is listed in Table 3. For the alkaline solution-to-binder ratio of 0.35 , the water absorption of AAFA mortars cured at higher temperatures (BM3, CM3, and DM3) varied from $5.2 \%$ to $5.9 \%$, whereas the water absorption of the AAFA mortar cured at ambient temperature (AM3) was $5.4 \%$. For the alkaline solution-to-binder ratio of 0.5 , the water absorption of AAFA mortars cured at higher temperatures (BM5, CM5, and DM5) ranged from $7.3 \%$ to $7.6 \%$ and was higher than that of the AAFA mortar cured at ambient temperature (AM5, water absorption $=6.7 \%)$. Similarly, for the alkaline solution-to-binder 

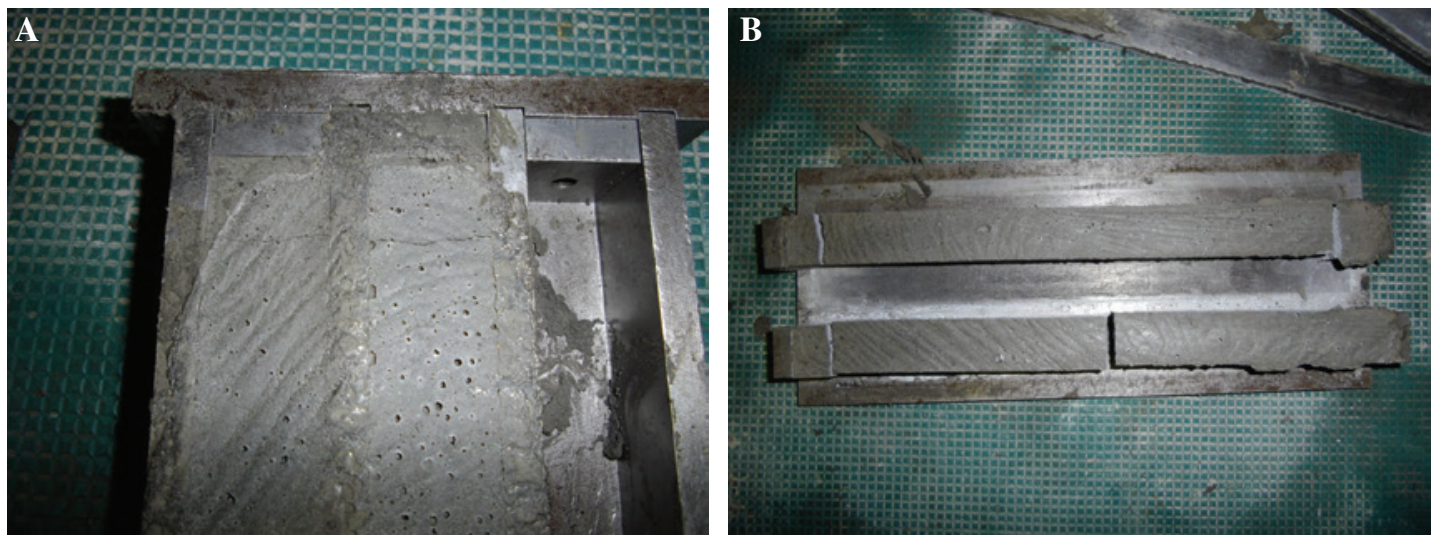

Figure 7: (A) Crack of AAFA mortars with alkaline solution to binder ratio of 0.65 cured at the temperature of $30^{\circ} \mathrm{C}$ for $24 \mathrm{~h}$. (B) Crack of AAFA mortars with alkaline solution to binder ratio of 0.65 cured at the temperature of $65^{\circ} \mathrm{C}$ for $12 \mathrm{~h}$.

ratio of 0.65 , the water absorption for AAFA mortars cured at higher temperatures (BM6, CM6, and DM6) was higher (varying between 9.6\% and 9.8\%) than that for the AAFA mortar cured at ambient temperature (AM6, water absorption $=8.9 \%$ ). Higher temperatures result in increased water absorption. It may be due to the crack formation during higher temperature curing. Furthermore, an increase in the alkaline solution-to-binder ratio increased the porosity and reduced the mechanical strength. As is evident from Table 3, the water absorption and porosity of AAFA mortars increased with the alkaline solution-to-binder ratio. Additionally, an increase in the curing temperature increased the water absorption and porosity of AAFA mortars. Thus, the alkaline solution to binder ratio and curing temperature played a crucial role in determining the water absorption and porosity of AAFA mortars.

Table 3: Water absorption and porosity of AAFA mortars.

\begin{tabular}{lrrr}
\hline Mix no. & $\begin{array}{r}\text { Water } \\
\text { absorption (\%) }\end{array}$ & $\begin{array}{r}\text { Relative } \\
\text { percentage (\%) }\end{array}$ & $\begin{array}{r}\text { Porosity } \\
\text { (\%) }\end{array}$ \\
\hline AM3 & 5.4 & - & 10.4 \\
BM3 & 5.2 & -0.2 & 10.5 \\
CM3 & 5.3 & -0.1 & 11.0 \\
DM3 & 5.9 & 0.5 & 12.1 \\
AM5 & 6.7 & - & 13.4 \\
BM5 & 7.3 & 0.6 & 14.1 \\
CM5 & 7.3 & 0.6 & 14.2 \\
DM5 & 7.6 & 0.9 & 14.7 \\
AM6 & 8.9 & - & 17.2 \\
BM6 & 9.6 & 0.7 & 18.2 \\
CM6 & 9.8 & 0.9 & 18.9 \\
DM6 & 9.7 & 0.8 & 18.4 \\
\hline
\end{tabular}

\subsection{Initial surface absorption test}

Variations in the initial surface absorption for testing times of 10, 30, and $60 \mathrm{~min}$ are plotted in Figures 8-10. It can be observed that the initial surface absorption of AAFA mortars decreased with an increase in the testing time. Figure 8 shows that for the alkaline solution-tobinder ratio of 0.35 (M3 mortars), the curing conditions did not appreciably influence the initial surface absorption of AAFA mortars; the reason is that M3 mortars are characterized by more effective alkali activation of fly ash, which results in their having a dense structure. Thus, the difference of initial surface absorption is not obvious for M3 mortars. The initial surface absorption of AAFA mortars with the alkaline solution-to-binder ratio of 0.5 (M5 mortars) is plotted in Figure 9. It can be seen that the

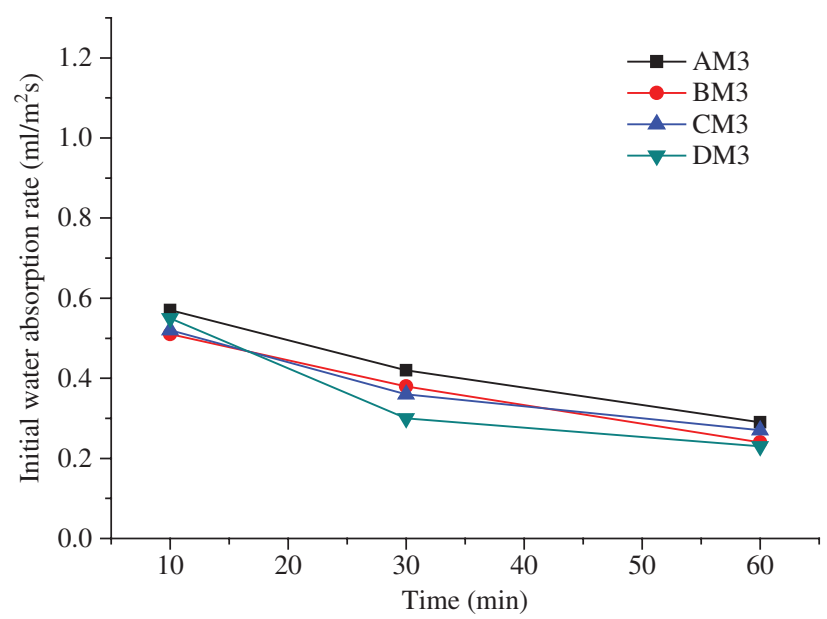

Figure 8: Initial surface absorption of AAFA geopolymer with the alkaline solution/binder ratio of 0.35 vs. time. 


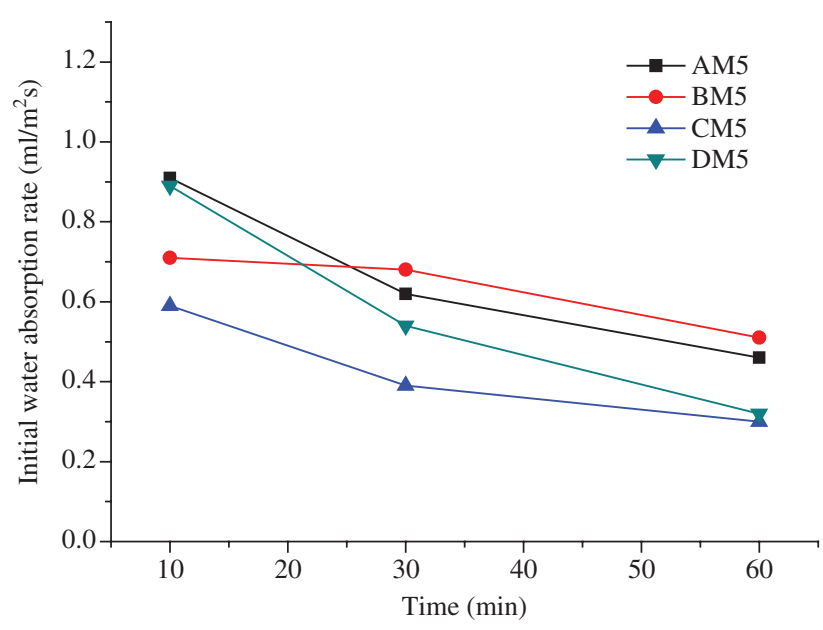

Figure 9: Initial surface absorption of AAFA geopolymer with the alkaline solution/binder ratio of $0.5 \mathrm{vs}$. time.

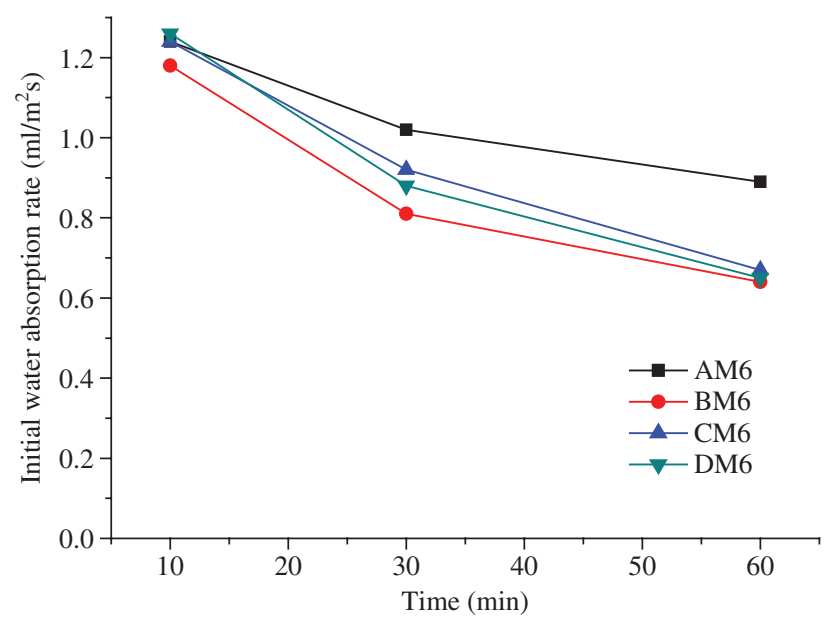

Figure 10: Initial surface absorption of AAFA geopolymer with the alkaline solution/binder ratio of 0.65 vs. time.

CM5 and DM5 mortars had lower initial surface absorption than AM5 and BM5 mortars, indicating that an increase in the curing temperature led to a decrease in the initial surface absorption. Figure 10 shows the initial surface absorption of AAFA mortars with the alkaline solutionto-binder ratio of 0.65 (M6 mortars); AM6 mortars showed the highest initial surface absorption (compared with the BM6, CM6, and DM6 mortars) for a testing time of 30 min. Thus, a high temperature can effectively reduce the initial surface absorption of M6 mortars. The trend of the initial surface absorption for M6 was similar to that for M5. However, the initial surface absorption of M6 was still considerably higher than that of the M3 and M5 mortars. These results indicate that a higher curing temperature and a lower alkaline solution-to-binder ratio lead to a reduction in initial surface absorption.

\subsection{Mercury intrusion porosimetry}

The mercury intrusion porosimetry test was performed to determine the pore structure of 28-day-old AAFA mortars. By tracking the applied pressure and intrusion volume at each increment, the cumulative intrusion volume, capillary pore intrusion volume, and gel pore intrusion volume of AAFA geopolymer mortars with the alkaline solution-tobinder ratio of 0.5 were obtained (Table 4). The cumulative intrusion volume of the AAFA mortars slightly increased with the curing temperature. AM5 (AAFA geopolymer mortars cured at ambient temperature) had the smallest cumulative intrusion volume, $0.1003 \mathrm{ml} / \mathrm{g}$ (capillary pore intrusion volume: $0.0911 \mathrm{ml} / \mathrm{g}$; gel pore intrusion volume: $0.0092 \mathrm{ml} / \mathrm{g}$ ). When AAFA mortars were cured at a lower temperature, the geopolymerization products gradually filled the pores in the basic structure, thereby, rendering the structure denser. By contrast, a higher cumulative intrusion volume, $0.1292 \mathrm{ml} / \mathrm{g}$ (capillary pore intrusion volume: $0.1198 \mathrm{ml} / \mathrm{g}$; gel pore intrusion volume: 0.0094 $\mathrm{ml} / \mathrm{g}$ ) was obtained for DM5 (AAFA geopolymer mortars cured at $\left.85^{\circ} \mathrm{C}\right)$. At higher temperatures, the final pore structure was almost realized within the first $24 \mathrm{~h}$, and it did not change during the aging of geopolymer [27]. The curing of AAFA mortars at high temperatures accelerates the formation of a hardened structure, particularly at early ages. When the process of hardening proceeds too quickly, it results in a less-ordered structure of poorer quality, and larger pores are left in the matrix. The porosimetry measurement results correspond closely with the water absorption and porosity results discussed in Section 3.3.

\subsection{X-ray diffraction analysis}

The reaction products were characterized mineralogically by XRD to identify the crystalline components in the

Table 4: Intrusion volume of mercury for AAFA mortars.

\begin{tabular}{lrrr}
\hline Mix no. & $\begin{array}{r}\text { Gel pore } \\
\text { intrusion } \\
\text { volume }(\mathrm{ml} / \mathrm{g})\end{array}$ & $\begin{array}{r}\text { Capillary pore } \\
\text { intrusion } \\
\text { volume }(\mathrm{ml} / \mathrm{g})\end{array}$ & $\begin{array}{r}\text { Cumulative } \\
\text { pore intrusion } \\
\text { volume }(\mathrm{ml} / \mathrm{g})\end{array}$ \\
\hline AM5 & 0.0092 & 0.0911 & 0.1003 \\
BM5 & 0.0094 & 0.0923 & 0.1017 \\
CM5 & 0.0099 & 0.1023 & 0.1122 \\
DM5 & 0.0094 & 0.1198 & 0.1292 \\
\hline
\end{tabular}




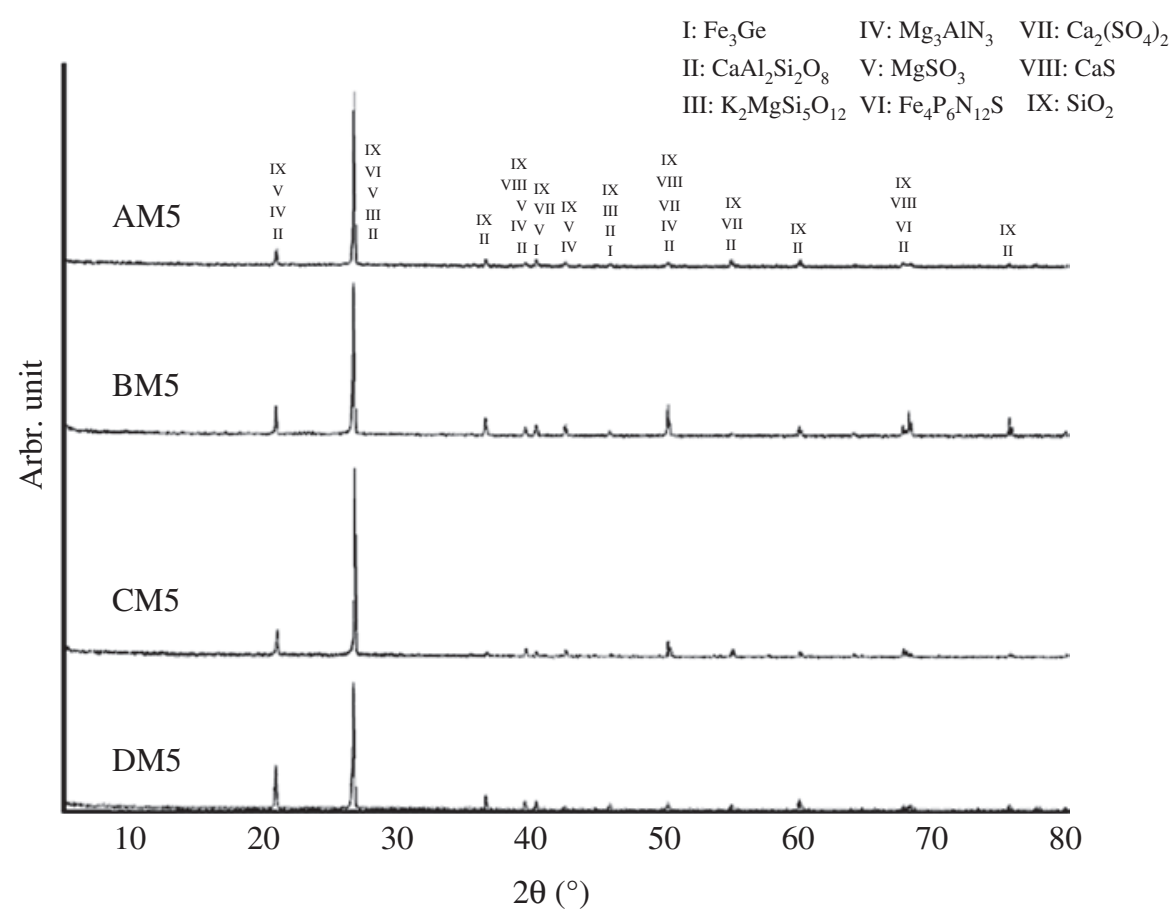

Figure 11: XRD patterns of AAFA geopolymer (alkaline solution/binder ratio of 0.5 ) with the various curing temperatures at the age 28 days.

system. Figure 11 shows XRD patterns of AAFA mortars (with the alkaline solution-to-binder ratio of 0.5) cured at different temperatures at the age of 28 days. The products of the reaction can be seen to be mostly amorphous, which was confirmed by a wide and diffusive reflection in the $2 \theta$ interval $21^{\circ}-45^{\circ}$. The hydration products of AAFA mortars are mainly amorphous alkaline aluminosilicate gel, which attributed to the compressive strength. The major crystalline phase in all AAFA geopolymer mortars was quartz $\left(\mathrm{SiO}_{2}\right)$ and zeolite gismondite $\left(\mathrm{CaAl}_{2} \mathrm{Si}_{2} \mathrm{O}_{8} \cdot 4 \mathrm{H}_{2} \mathrm{O}\right)$. Other phases such as magnesium sulfite $\left(\mathrm{MgSO}_{3}\right)$, calcium sulfide (CaS), magnesium-aluminum nitrides $\left(\mathrm{Mg}_{3} \mathrm{AlN}_{3}\right)$, anhydrite $\left(\mathrm{CaSO}_{4}\right)$, magnetite $\left(\mathrm{Fe}_{3} \mathrm{O}_{4}\right)$, leucite structure group $\left(\mathrm{K}_{2} \mathrm{MgSi}_{5} \mathrm{O}_{12}\right)$, and iron phosphorus nitride $\left(\mathrm{Fe}_{4} \mathrm{P}_{6} \mathrm{~N}_{12} \mathrm{~S}\right)$ were also present. The major identified crystalline peaks corresponded to quartz and zeolite gismondite attributed to the effect of the fly ash components in the crystalline phase were observed at $27^{\circ} 2 \theta$, which are similar to those of most previous research $[4,10,12,45,46]$. In addition, DM5 (AAFA mortars cured at $85^{\circ} \mathrm{C}$ ) showed a peak intensity lower than those of the other three AAFA mortars cured at temperatures from ambient temperature to $65^{\circ} \mathrm{C}$ (AM5, BM5, and CM5). Higher curing temperatures may accelerate the geopolymerization reaction and cause the formation of amorphous alumina-silicate substances at early ages. However, the growth of zeolite crystals is slow at late ages, and therefore, the amorphous products are stabilized at early ages. Thus, the peak intensity for DM5 decreased.

\section{Conclusions}

This study investigated the effect of curing temperature on the properties of AAFA mortars. The main conclusions were as follows:

1. The lower the alkaline solution-to-binder ratio, the higher the compressive strength and the lower the drying shrinkage. Furthermore, the curing temperature influenced the compressive strength development and drying shrinkage of AAFA mortars at early ages, particularly for AAFA mortars with the alkaline solution-to-binder ratios of 0.5 and 0.65 .

2. A higher temperature led to more effective alkali activation of fly ash, but resulted in increased water absorption. An increase in the alkaline solution-tobinder ratio increased the porosity and degraded the mechanical properties.

3. A high curing temperature and a low alkaline solution-to-binder ratio led to a decrease in the initial surface absorption.

4. XRD demonstrates that the hydration products of AAFA mortars are mainly amorphous alkaline aluminosilicate gel, which attributed to the compressive 
strength. The major crystalline phase of AAFA geopolymer mortars consisted of quartz, zeolite gismondite, mullite, magnesium sulfite, magnetite, anhydrite, and feldspar.

5. AAFA mortars cured at $65^{\circ} \mathrm{C}$ for $12 \mathrm{~h}$ appeared to have superior mechanical properties.

Acknowledgments: The author would like to thank the Ministry of Science and Technology (MOST) of Taiwan for Granting the Project under No. NSC-99-2221-E-274-010.

\section{References}

[1] Palomo A, Grutzeck MW, Blanco MT. Cem. Concr. Res. 1999, 29, 1323-1329.

[2] Criado M, Fernández-Jiménez A, Palomo A. Fuel 2010, 89, 3185-3192.

[3] Vargas ASd, Molin DCCD, Vilela ACF, Silva FJd, Pavão B, Veit H. Cem. Concr. Compos. 2011, 33, 653-660.

[4] Jun Y, Oh JE. Cem. Concr. Res. 2014, 52, 396-403.

[5] Bakharev, T. Cem. Concr. Res. 2005, 35, 1224-1232.

[6] Němecěk, Jí, Šmilauer V, Kopecký L. Cem. Concr. Compos. 2011, 33, 163-170.

[7] Pacheco-Torgal F, Castro-Gomes Jo, Jalali S. Constr. Build. Mater. 2008, 22, 1305-1314.

[8] Hu M, Zhu X, Long F. Cem. Concr. Compos. 2009, 31, 762-768.

[9] Somaratna J, Ravikumar D, Neithalath N. Cem. Concr. Res. 2010, 40, 1688-1696.

[10] Torres-Carrasco M, Puertas F. J. Clean. Prod. 2015, 90, 397-408.

[11] Chi M, Liu Y, Huang R. IACSIT Inter. J. Eng. Tech. 2015, 7, 59-64.

[12] Ryu GS, Lee YB, Koh KT, Chung YS. Constr. Build. Mater. 2013, 47, 409-418.

[13] Wang J, Wu X-l, Wang J-x, Liu C-z, Lai Ym, Hong Z-K. Micropo. Mesopo. Mat. 2012, 155, 186-191.

[14] Criado M, Jiménez AF, Sobrados I, Palomo A, Sanz J. J. Eur. Ceram. Socy. 2012, 32, 2799-2807.

[15] Chi M, Huang R. Adv. Sci. Lett. 2012, 16, 7-12.

[16] Vladimir Z. Constr. Build. Mater. 2007, 21, 1463-1469.

[17] Odler I, Röbler M. Cem. Concr. Res. 1985, 15, 401-410.

[18] Schulze J. Cem. Concr. Res. 1999, 29, 909-915.

[19] Provis JL, Yong CZ, Duxon P, van Deventer JSJ. Colloids. Surf. A. 2009, 336, 57-63.
[20] Zuhua Z, Xiao Y, Huajun Z, Yue C. Appl. Clay Sci. 2009, 43, 218-223.

[21] Xiao Y, Zuhua Z, Huajun Z, Yue C. Thermochim. Acta 2009, 493, 49-54.

[22] Ruiz-Santaquiteria C, Skibsted J, Fernández-Jiménez A, Palomo A. Cem. Concr. Res. 2012, 42, 1242-1251.

[23] Oh JE, Monteiro PJM, Jun SS, Choi S, Clark SM. Cem. Concr. Res. 2010, 40, 189-196.

[24] Ravikumar D, Peethamparan S, Neithalath N. Cem. Concr. Compos. 2010, 32, 399-410.

[25] Khale D, Chaudhary R. J. Mater. Sci. 2007, 42, 729-746.

[26] Criado M, Fernández-Jiménez A, Palomo A. Micropo. Mesopo. Mat. 2007, 106, 180-191.

[27] Rovnaník P. Constr. Build. Mater. 2010, 24, 1176-1183.

[28] Kovalchuk G, Fernández-Jiménez A, Palomo A. Fuel 2007, 86, 315-322.

[29] Swanepoel J, Strydom C. Appl. Geochem. 2002, 17, 1143-1148.

[30] Chi M. Constr. Build. Mater. 2012, 35, 240-245.

[31] Palomo Á, Alonso S, Fernández-Jiménez A, Sobrados I, Sanz J. J. Am. Ceram. Soc. 2004, 87, 1141-1145.

[32] Fernández-Jiménez A, Palomo A. Fuel 2003, 82, 2259-2265.

[33] Jaarsveld Jv, Deventer Jv. Ind. Eng. Chem. Res. 1999, 38, 3932-3941.

[34] ASTM C778 Standard Specification for Standard Sand. 2013.

[35] Sievert T, Wolter A, Singh NB. Cem. Concr. Res. 2005, 35, 623-630.

[36] ASTM C109 Standard Test Method for Compressive Strength of Hydraulic Cement Mortars. 2011.

[37] ASTM C596 Standard Test Method for Drying Shrinkage of Mortar containing Hydraulic Cement. 2009.

[38] ASTM C642 Standard Test Method for Density, Absorption, and Voids in Hardened Concrete. 2006.

[39] Collins F, Sanjayan JG. Cem. Concr. Res. 1999, 29, 607-610.

[40] Li H-j, Sun H-H. Int. J. Miner. Metal. Mater. 2009, 16, 482-486.

[41] BS 1881-201 Testing concrete. Method for determination of water absorption. 1986.

[42] ASTM D4404 Standard Test Method for Determination of Pore Volume and Pore Volume Distribution of Soil and Rock by Mercury Intrusion Porosimetry. 2010.

[43] Kumar R, Bhattacharjee B. Cem. Concr. Res. 2003, 33, 417-424.

[44] Fedrizzi L, Azzolini F, Bonora PL. Cem. Concr. Res. 2005, 35, 551-561.

[45] Nath SK, Kumar S. Constr. Build. Mater. 2013, 38, 924-930.

[46] Komljenović M, Baščarević Z, Bradić V. J. Hazar. Mater. 2010, $181,35-42$. 